\title{
Engineering solutions for heart efficient exterior walls in climatic condition of the Republic of Bashkortostan
}

\author{
Anatoly Bedov ${ }^{1}$, Azat Gabitov ${ }^{2}$, Askar Gaysin ${ }^{2}$ and Alexander Salov ${ }^{2, *}$ \\ ${ }^{1}$ Moscow State University of Civil Engineering, Yaroslavskoe shosse, 26, Moscow, 129337, Russia \\ ${ }^{2}$ Ufa State Petroleum Technological University, Mendeleeva St. 195, Ufa, 450000, Russia
}

\begin{abstract}
Problems and disadvantages of some technical solutions concerning modern heat efficient exterior walls are considered herein under experience of engineering, construction and operation of residential and civil buildings in the Republic of Bashkortostan. Special attention is paid to defects in engineering and erection of three-layer walls, and functioning principles of all components of the wall are strictly fixed. Recommendation to increase maintenance-free service life by meeting special engineering requirements are given herein. Effect to increase buildings heat insulation is achieved by: reducing heat loss through separate enclosing structures and heat insulating shells of the building thereby enabling to reduce thermal power requirements; improving heat acceptability in rooms by decreasing rate of radiative and convective heat exchange in outer surface of enclosures; reducing environmental pollution due to air emissions reduction. Exterior wall insulation is the important element of the building heat balance. Many researchers in this field currently focus on analysis of series of residential buildings with different number of storeys made by engineering solutions for exterior walls to increase heat homogeneity thereof.
\end{abstract}

Subject: main engineering solutions for heat efficient exterior walls. Objectives: three-layer wall constructed of masonry units; exterior threelayer wall within 121 u panel series; three-layer wall of "Ventilated façade" system; façade heat insulation with plaster on lath; wall made of loadbearing structural insulating materials.

Materials and methods: calculation of reduced total thermal resistance in exterior walls.

Results: one of the most efficient methods to meet specific heat-shielding performance requirements is to increase heat homogeneity of the exterior wall.

Conclusions: in the short term structural components of three-layer exterior walls are to be upgraded according to construction rules and regulations SNiP 23-02-2003 "Buildings Heat Insulation" thereby enabling the engineering solutions to meet the appropriate norms and rules.

* Corresponding author: salov@list.ru 


\section{Introduction}

A problem to increase energy efficiency of domestic housing stock refers both to slum dwelling inherited from the former USSR and to numerous housing and public facilities built in post-Soviet period. Therefore, the major changes in regulatory requirements to building heat insulation started from amendment 3 to SNiP II-3-79 "Construction heat engineering" of September 1, 1995 were sure to be reasonable. As indicated in [1] the frames with thermal resistance level by 3.5 times higher than in monolayer 2.5-brick walls, or $400 \mathrm{~mm}$ monolayer LECA block were required. This fact gave rise to development and realization of actually new engineering solutions to enclosing structures in relation to previous 50-year construction experience in former USSR.

\section{Bibliography}

The following main engineering solutions to heat efficient exterior walls with 15-20 years operating experience may be emphasized in Ufa and the Republic of Bashkortostan: threelayer wall constructed of masonry units; exterior three-layer wall of $121 \mathrm{u}$ panel series; three-layer wall of "Ventilated façade" system; façade heat insulation with plaster on lath; wall made of load-bearing structural insulating materials.

\section{Materials and methods}

Three-layer wall constructed of masonry units includes base and facing layers from standard bricks or vibropressed concrete bricks with a middle layer of efficient heat insulation. Foam polystyrene, mineral wool and fiber-glass are applied as heat insulation. Both inside and outside layers are connected by flexible braces (corrosion-resistant steel wire, basalt-plastic and fiber-glass braces). There is an air space between cladding and heat insulation, acting as ventilation in three-layer wall. Such walls have been manufactured by OAO "Krupnopanelnoe Domostroenie" for many years. This company constructs residential and various civil buildings of up to 16 storeys in Ufa and the Republic of Bashkortostan basically applying besser blocks. By structural survey of operated buildings with this engineering solution for exterior walls the following frequently occurred defects may be singled out: temperature-shrinkage cracking, leaks and efflorescence in metal support bracket areas for cladding and flexible braces not protected against corrosion. Department "Engineering Structures" at USPTU together with BashNIPIstroi institution have issued several regulatory documents on this engineering solution, including Regional construction norms for calculation and engineering, recommendations on construction technology and several technical solution books, a book of reinforced support structures for multi-storey cladding is prepared to be published.

Exterior three-layer wall within $121 \mathrm{u}$ panel series includes internal base layer as a dense concrete panel to be installed on reinforced console perforated bracket, heat insulation layer and $1 / 2$ brick facing layer or vibropressed concrete block to be placed on the same support bracket. Both facing and inside layers are connected by flexible braces. Other solution for making cladding is $100 \mathrm{~mm}$ panel. On the whole the construction proved to be good and justified. It enabled to maintain large-panel house construction in Ufa in amount of about $100,000 \mathrm{~m} 2 /$ year.

This kind of wall as compared with heat efficient wall constructed of masonry units has both advantages and disadvantages. Labor saving by $10-20 \%$ and reduction of time for wall assembling which results in cutting of panel wall erection costs by $5-15 \%$, provided assembling is good and quality materials (heat insulation, flexible braces, inserts, etc.) are 
used may be referred to advantages. Bad reliability of the support bracket performed as a frame from structural LECA blocks is disadvantage of $121 \mathrm{u}$ panel series which predetermines operating reliability of panel buildings of this series for at least 20-30 years throughout the wall elements. Main reason for weak reliability of panel walls are poor engineering solutions and bad quality of construction and erection work according to the structural survey of operated buildings.

Three-layer wall of "Ventilated façade" system is basically realized in Ufa in two kinds: by "Marmoroc" and "Kraspan" systems. The construction is well combined with reinforced frame and includes inside layer made from any structural material (filler wall if combined with the frame), system of fittings in the galvanized metal, heat insulation layer and facing screen going outside for air space thickness. Advantage of the system is all-season construction as there are no wet processes; high maintainability (several sheets of the problem area of exterior walls may be easily dismantled and the screen may be put back afterwards); efficient and quick elimination of any kind of moisture by high-speed air circulation within the air space.

Disadvantages of three-layer wall of "Ventilated façade" system after analyzing experience in engineering, construction and operation of buildings are: higher cost as compared with other wall insulation systems; low heat transfer performance uniformity factor of the enclosing structure due to availability of many thermal bridges in the area for fixing metal fittings to the base; complexity of the system in making it requiring more strict geodetic support and geometry of the building itself and high quality of metal fittings; high requirements to the foundation position (careful selection of anchors to fix metal fittings to the base); amount of various operations in assembling façade systems requiring high professionalism from the builders thereby complicating quality control for the work.

Façade heat insulation with plaster on lath includes internal base layer, heat insulation layer and facing layer as a plastering system. Currently, "Senardgy" system and domestic "LAES" system are prevailing in Ufa to some extent, but majority of facilities is erected by OOO "Bashneftezavodstroy" under "Baumit" Austrian technology.

Reliability of façade heat insulation is stipulated by operation capacity of façade plasters in the system of adhesive fixing heat insulation, of base layer with synthetic mesh inside, of primer and finishing coats. It should be mentioned that textured details in the façade are badly combined with façade heat insulation with plaster on lath. Moisture, melting ice and snow may gather on these details thereby resulting in plaster damage due to continuous moistening and defrosting thereof.

Another important direction in applying façade heat insulation systems is renovation of old residential panel and brick houses of 50-80s series. The important element of renovation is external insulation, and façade insulation is applied hereto as it makes no extra load.

Operating experience with façade heat insulation has demonstrated that resistance of façade waterproof plaster is the main reason for the system reliability. Criterion of system failure in this case is plaster damage, with the exposed insulation retaining physical-andmechanical and heat properties thereof for some time. Other factors affecting operating reliability and durability of plaster are: deformation of plaster covering with shrinkage and variations in temperature; moisture accumulation inside the wall within annual period of operations and excess moistening thereof accompanied by condensate formation in winter periods; moistening of the wall exposed to weather during transition "winter-autumn" and "autumn-winter" periods which is dangerous by excess moistening of the plaster covering with periodic cycle of freezing and thawing.

Wall made of load-bearing structural insulating materials (cellular-concrete blocks) may be fabricated of both cellular-concrete blocks and aerated large-size ceramic blocks. Walls made of cellular-concrete blocks have proved to be reliable when applied in construction of 
farmhouses in 60s of the last century in the southern part of the Republic of Bashkortostan. At that time pilot production of autoclaved gas-concrete blocks made from solid residues of soda production was launched in OAO "Soda". Cellular-concrete blocks with average density of $400-600 \mathrm{~kg} / \mathrm{m} 3$ provide for $40-60 \mathrm{~cm}$ thickness of the exterior wall in climatic conditions of the Republic of Bashkortostan.

BashNIPIstroi institution together with Department "Engineering Structures" at USPTU have prepared a manual with engineering solutions for exterior walls made of autoclaved gas-concrete blocks, where protection of the walls against destructive factors is proposed to be provided as follows:

facing by $1 / 2$ solid ceramic bricks, vibropressed concrete $90 \mathrm{~mm}$ blocks (besser block with $30 \%$ hollowness)(in combination with gas-concrete blocks $\gamma=400 \mathrm{~kg} / \mathrm{m} 3$ );

strengthened composite waterproof plaster (base plaster layer is fabric-reinforced) in combination with gas-concrete blocks $\gamma=500 \mathrm{~kg} / \mathrm{m} 3$ );

moderate waterproof plaster or water-repellant treatment (in combination with gasconcrete blocks $\gamma>600 \mathrm{~kg} / \mathrm{m} 3$ ).

The proposed solutions for $400 \mathrm{~mm}$ filler-walls of framed buildings to be faced both with besser blocks and face decorative and protective "Baimit" system realized in several 16-storey residential houses have demonstrated operational integrity thereof by heat insulation, room conditions and interior plain of the walls. Production line of autoclaved gas-concrete blocks with output of 240,000 m3 commissioned in 2010 in Bashkortostan contributed largely to application of exterior walls in the indicated heat efficient materials.

Walls made of aerated large-size ceramic blocks are less applicable in climatic conditions of the Republic of Bashkortostan and are currently being studied by the authors [3-5].

Crisis events in domestic construction branch, as well as poor engineering solutions and low quality of construction and erection work, poor development of the construction industry in some regions, etc. [6-9] when making radical changes (adopted in 1995) to regulatory requirements to building heat insulation have caused heat engineering norms to be constantly changed. Recent Russian standards as SP 50.13330.2012 "Building heat insulation" are considering the advanced experience and are more close to real conditions $[10,11]$.

According to SP 50.13330.2012 "Building heat insulation" the reduced total thermal resistance in a section of heat insulation shell $\mathrm{R} 0 \Pi \mathrm{np},\left(\mathrm{m} 2 \cdot{ }^{\circ} \mathrm{C}\right) / \mathrm{W}$ is calculated by a procedure indicated in Amendment $\mathrm{E}$ using results of temperature field calculation. Therewith, the reduced total thermal resistance in exterior walls is to be calculated for all façade parts considering jambs with no filling thereof by formula (1):

$$
R_{o}^{\mathrm{mp}}=\frac{1}{\frac{1}{R_{o}^{\text {ycr }}}+\sum l_{j} \Psi_{j}+\sum n_{k} \chi_{k}}=\frac{1}{\sum a_{i} U_{i}+\sum l_{j} \Psi_{j}+\sum n_{k} \chi_{k}},
$$

where, $1 \mathrm{j}, \mathrm{nk}$ - geometry of elements to be defined for certain project;

$\Psi \mathrm{j}, \chi \mathrm{k}$ - specific heat loss through elements;

$R_{o}^{\mathrm{ycr}}$ of the building or to a separated enclosing structure, $\mathrm{m} 2{ }^{\circ} \mathrm{C} / \mathrm{W}$;

Ui - coefficient of heat transmission of homogeneous $\mathrm{i}$-th part of the building heat insulation shell section (specific heat loss through flat element of i-th kind), $\mathrm{W} /\left(\mathrm{m} 2{ }^{\circ} \mathrm{C}\right)$;

ai - area of flat element of $i$-th kind falling on $1 \mathrm{~m} 2$ of the building heat insulation shell section or indicated enclosing structure, $\mathrm{m} 2 / \mathrm{m} 2$.

The calculation is based on presentation of a building heat insulation shell section as a range of separate elements affecting heat loss through the section. Specific heat loss from each element is found by comparing heat flowing through the area containing the element 
and through the same area but with no element analyzed. As a rule, exterior walls are considered the most nonhomogeneous section of the heat insulation shell of a building.

According to SP 50.13330.2012 "Building heat insulation" requirements the reference value of normalized heat transfer resistance in residential building walls in climatic conditions of the Republic of Bashkortostan is about R0norm $\approx 3.41 \mathrm{~m}^{2} \cdot{ }^{\circ} \mathrm{C} / \mathrm{W}$. On the whole, as per the building design with above mentioned exterior wall construction in Ufa, total thermal resistance for engineering design of three-layer exterior walls (both loadbearing walls and filler-walls) complies with base levels, and heat transfer resistance in filler-walls applying autoclaved gas-concrete blocks or large-size porous ceramic blocks is a bit lower than the base layer, but markedly higher than minimum acceptable level (considering regional factor $\mathrm{mp}=0.63$ ). Applicability of engineering solutions for exterior walls with lower level of heat insulation but with acceptable specific heat loss value was justified by a number of authors $[6,12]$.

\section{Results}

The authors have analyzed the presented engineering solutions for exterior multi-layer heat efficient walls of residential 12-17-storeyed houses in Ufa (except for three-layer walls of $121 \mathrm{u}$ panel series) designed by the procedure of out-of-day SNiP 23-02-2003 version "Building heat insulation" and erected 8-10 years ago according to SP 50.13330.2012 "Building heat insulation" requirements [13], as the indicated designs for buildings are still implemented nowadays. On the whole, thermal resistance level complies with reference rated level for the Republic of Bashkortostan, and the buildings under review may be referred to "normal" E class for energy efficiency by specific heat loss for heating and ventilation at the project phase. Analysis of specific heat-shielding performance calculations in accordance with SP 50.13330.2012 "Building heat insulation" has demonstrated that the greatest specific heat loss through the enclosure falls on exterior walls (about 60\%), windows and balcony doors (about 30\%).

It should be emphasized that heat engineering nonhomogeneities under calculation of reduced total thermal resistance have been covered by tabular method as per simplified procedure SP 230.1325800.2015 "Enclosing structures. Characteristics for heat engineering nonhomogeneities", that has already been tested by some authors and adequate accuracy thereof for engineering calculations has been justified [14, 15]. Approximate share of heat loss through exterior wall elements is as follows: along the wall surface $-62 \%$, window unit and wall junction $-12 \%$, balcony slab and wall junction $-6 \%$, cast-in-situ strips to be veneered $-4 \%$, flexible braces $-16 \%$.

According to further analysis the value for reduced total thermal resistance in façade of the wall, i.e. considering all heat transfer inclusions, is to be at least $2.65 \mathrm{~m}^{2} \cdot{ }^{\circ} \mathrm{C} / \mathrm{W}$ (Figure 1) for buildings with area to be heated of approximately $V_{\text {heat }} \approx 20000-22000 \mathrm{~m}^{3}$, provided reduced total thermal resistance in windows and balcony doors, as well as in garret floor and in floor over unheated basement are met by rated base levels to comply with specific heat-shielding performance requirements. It means that if heat transfer homogeneity factor of exterior three-layer wall of the building falls within $\mathrm{r}=0.63-0.68$ range, heat thermal resistance level of the wall along the surface is to be $3.82-4.13 \mathrm{~m}^{2} \cdot{ }^{\circ} \mathrm{C} / \mathrm{W}$, therefore requiring increase of the wall thickness to $140-160 \mathrm{~mm}$ with coefficient of heat conductivity of $\lambda=0.042 \mathrm{~W} /\left[\mathrm{m}^{2} \cdot{ }^{\circ} \mathrm{C}\right]$. Such change of the wall engineering solution is actually possible for the account of reducing air space thickness but seems to be inefficient. In general, the exterior wall consisting of load-bearing structural insulating materials will require extra efficient heat insulation [13]. 


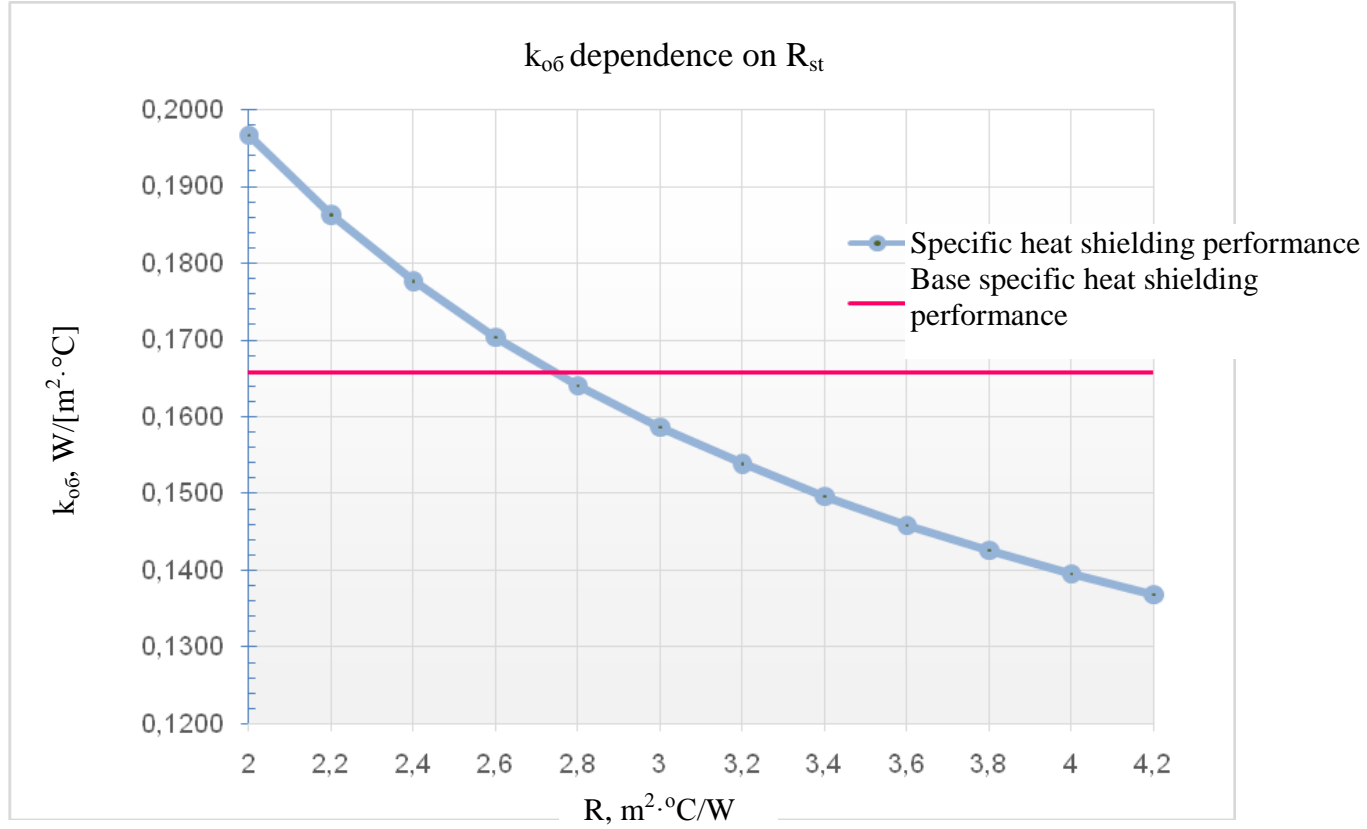

Fig. 1. Specific thermal heating value $\mathrm{k}_{\text {об }}$ dependence on heat transfer resistance in exterior walls $\mathrm{R}_{\text {ст. }}$

According to some authors $[13,17,18]$ increase of heat engineering homogeneity of exterior three-layer walls of the analyzed buildings is the most efficient method to comply with specific heat shielding performance requirements. In our case it is bringing of the heat transfer homogeneity factor to $r=0.74-0.77$. Share of total heat flow through $1 D$ and $0 D$ elements (heat transfer inclusions) add up to $38 \%$, i.e. upgrading in jambs, balcony slab/wall junctions and cast-in-situ strips to be veneered, as well as transition from metal flexible braces to fiber-glass ones may be considered as additional ways to increase heat engineering homogeneity of exterior three-layer walls in the analyzed projects.

For example, our research of jambs in exterior three-layer walls of tall buildings [19] (three-layer wall constructed of masonry units; three-layer wall of "Ventilated façade" system; façade heat insulation with plaster on lath; wall made of load-bearing structural insulating materials) has revealed that increase of insulation/frame overlapping by each $2.5 \mathrm{~cm}$ (when the jamb is directly behind the insulation layer, see Fig.2) results in increase of heat engineering homogeneity of exterior walls along the façade by approximately $3 \%$, accordingly. 


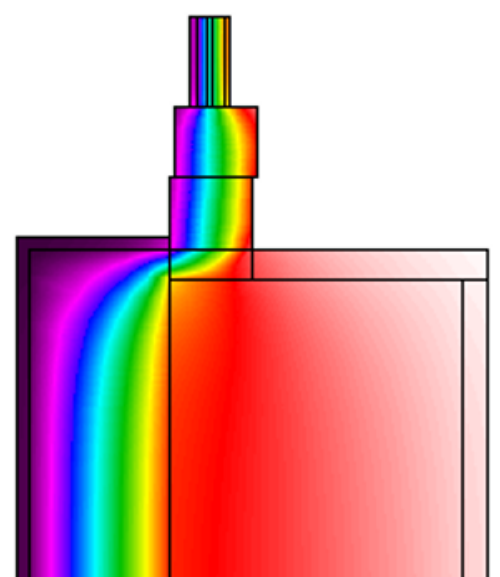

Fig. 2. Temperature distribution in window sill section of three-layer wall subject to insulation frame overlapping.

\section{Conclusion}

Therefore, analysis of solutions for exterior three-layer load-bearing walls of residential series for 12-17-storeyed houses (except for three-layer walls of $121 \mathrm{u}$ panel series) to be erected in Ufa according to the procedure of out-of-day SNiP 23-02-2003 version "Building heat insulation" with regard to requirements of updated regulatory documents has demonstrated that they may be implemented now but some updating of structural components in heat efficient exterior three-layer load-bearing walls to eliminate major heat transfer inclusions is required.

In the immediate future the authors will focus on making the similar analysis of projects for residential series of 17-20-storeyed buildings with filler walls applying load-bearing structural insulating materials.

\section{References}

1. R. Mamleev, R. Sagitov, G. Kolesnik, Const. mater. 10, 6-10 (2003)

2. V.Babkov, D.Kuznetsov, Y.Morozova, Engin. syst. 11, 14-16 (2010)

3. V.Gagarin. Const. mater. 3, 8-16. 2010.

4. A. Bedov, A. Gaisin, A. Gabitov, News of high.educ.instit. Text.ind.tech. 3, 215-220 (2017)

5. A. Bedov, A. Gaisin, A. Gabitov, D. Kuznetsov, A. Salov, Y. Abdulatipova, Bullet.MGSU. Vol.12, 17-25 (2017)

6. A. Bedov, A. Gabitov, A. Gaisin, A. Salov, A. Chernova, IOP Conf.Ser.: Mater.Scien. and Engin.. Vol. 465, 1-7, (2018)

7. V. Babkov, A. Gaisin, R. Gareev, G. Kolesnik, Const. mater. 5, $43-47$ (2006)

8. V. Babkov, E.Gafurova, O. Rezvov, Constr. mater. 11, 74-77 (2012)

9. I. Nedoseko, V. Babkov, R. Aliev, V. Kuzmin, Hous. constr. 3, 26-28 (2008)

10. V. Gagarin, V. Kozlov, Hous.constr. 8, 2-7 (2011)

11. V. Gagarin, K. Dmitriev, Constr. mater. 3, 14-16 (2013)

12. O. Samarin, Hous. Constr. 3, 46-48 (2014)

13. V. Babkov, R. Khusnutdinov, A. Chuikin, A. Gaisin, R. Gareev, SPb.: Nedra. 180 (2011) 
14. A. Bedov, A. Gabitov, A. Gallyamov, A. Salov, A. Gaisin, Intern. Jour. for Comp. Civ. and Struc.Engin. 1, 42-49 (2017)

15. A. Bedov, A. Gabitov, A. Gaisin, A. Salov, A. Chernova, VI Intern. Scien. Conf. (IPICSE-2018), 1-7 (2018)

16. A. Bedov, A. Gabitov, A. Gaisin, A. Salov, A. Chernova, IOP Conf. Ser.: Mater. Scien. and Engin. Vol. 465, 1-8 (2018)

17. A. Gaisin, S. Samokhodova, I. Nedoseko, A. Paymetkina, Resid. Constr. 5, 36-40 (2016)

18. N. Umnyakova, T. Egorova, V. Cherkas, P. Belogurov, K. Andreitseva, Constr.mater. 6, 17-19 (2012)

19. R. Galeev, A. Gaisin, M. Shibirkina, D. Sinitsyn, A. Salov, registr. RUS 2016612591, righthold. FGBOU VPO UGNTU (2016)

20. A. Bedov, A. Gaisin, A. Gabitov, A. Salov, S. Samokhodova, 12, 28-32 